\title{
Effect of Addition of Fine SiC Particles on the Dry Sliding Wear Behaviour of Extruded 2014 Al-Alloy
}

\author{
Rupa Dasgupta, A. K. Jha, and S. Das \\ CSIR-AMPRI, Madhya Pradesh, Bhopal 462064, India \\ Correspondence should be addressed to Rupa Dasgupta; rupa_dasgupta@rediffmail.com
}

Received 17 October 2012; Accepted 11 November 2012

Academic Editors: V. P. Astakhov, N. Bagcivan, and M. Dienwiebel

Copyright (C) 2013 Rupa Dasgupta et al. This is an open access article distributed under the Creative Commons Attribution License, which permits unrestricted use, distribution, and reproduction in any medium, provided the original work is properly cited.

\begin{abstract}
Composites of 2014 alloy made by dispersing 10 vol.\% of fine $(20-50 \mu \mathrm{m}) \mathrm{SiC}$ particles using vortex method ensuring uniform distribution of $\mathrm{SiC}$ particles in the matrix have shown uniform distribution of $\mathrm{SiC}$ particles. Mechanical properties of the composites have also registered an improvement over the alloy. In an attempt to further improve the properties, the composites were subjected to hot extrusion of cylindrical rods along with the alloys under similar experimental conditions. A temperature range of $300-350^{\circ} \mathrm{C}$ and an extrusion ratio of 10:1 were maintained during the process. The extruded samples were compared for their mechanical properties, and improvement was noted. The mechanism of material failure from fractographic studies showed difference in behaviour between the alloy and composite. Dry sliding wear studies carried out on extruded specimens exhibited improved wear behaviour in composites over alloys as measured by volume loss and wear rate. Wear mechanism was studied from the worn surface and correlated with the wear performance. It was observed that the presence of $\mathrm{SiC}$ particles reduces the tendency of delamination and thus material removal from the wear surface.
\end{abstract}

\section{Introduction}

Worldwide, researchers have repeatedly demonstrated on a laboratory scale, attractive properties in aluminium-based metal matrix composites with $\mathrm{SiC}$ dispersoids. The property improvements relate to microstructural, mechanical properties such as specific modulus, strength, and wear resistance, in addition to a service temperature capability in selected aluminium-based composites with selected second phase dispersoids. It is an open knowledge for researchers in this field now as to the alloy systems, second phase's nature, volume fraction, and fabrication routes that can exhibit improved performance. The properties attained are so attractive that these materials hold potential for applications in aerospace, automotive, electronic, sports, ballistic protection, and other general engineering fields [1-14]. However, the expectation to see the MMCs as engineering products would need their mass production and confidence in the ability to subject these materials to secondary processing while maintaining the improved properties attained in the cast condition. Open literature regarding mass production is seldom reported. Attempts at secondary processing of Al-based MMCs especially through extrusion to deform the materials into desired shapes and refine the microstructure are being reported substantially now [15-22]; the extruded MMCs exhibit uniform reinforced distribution, reduced porosity, finer grain structures, improved mechanical and physical properties, and improved bonding as compared to the cast products.

1.1. Property Evaluation. Challenges of extruding Al-based MMCs have been overcome by the authors in the past and optimised conditions for extrusion established [23]. The present paper reports the effect of extrusion under optimised conditions on a 2014 based aluminium alloy and its composite made with $10 \mathrm{vol} . \% \mathrm{SiC}$ dispersoids and compares the properties, namely, microstructure, mechanical and dry 


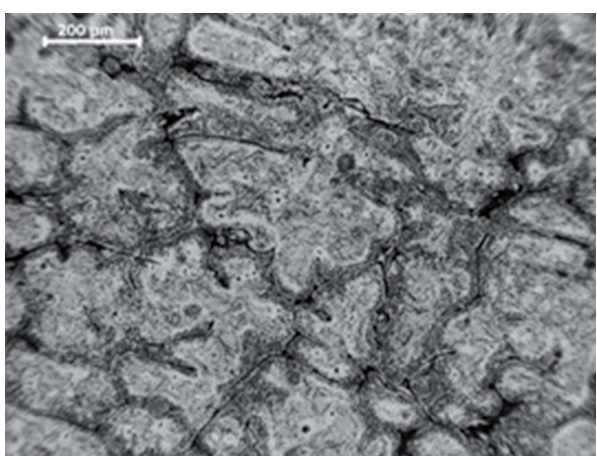

(a)

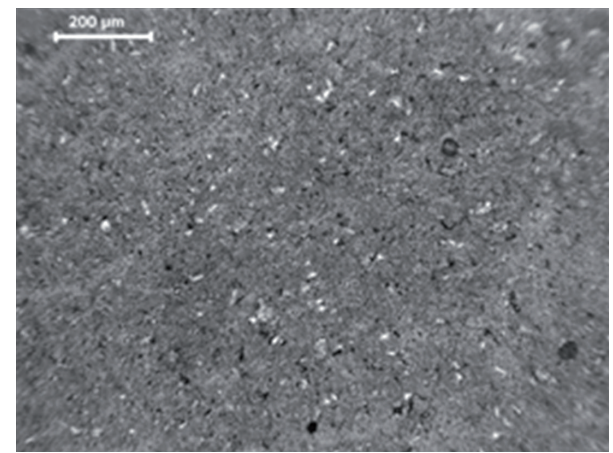

(b)

FIGURE 1: Microstructure of alloy.

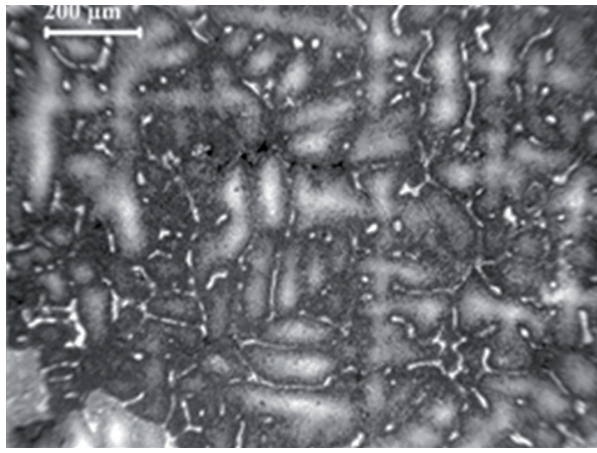

(a)

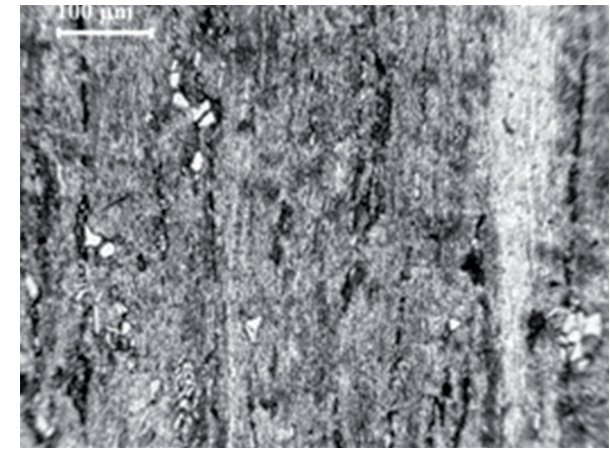

(b)

Figure 2: Microstructure of Composite.

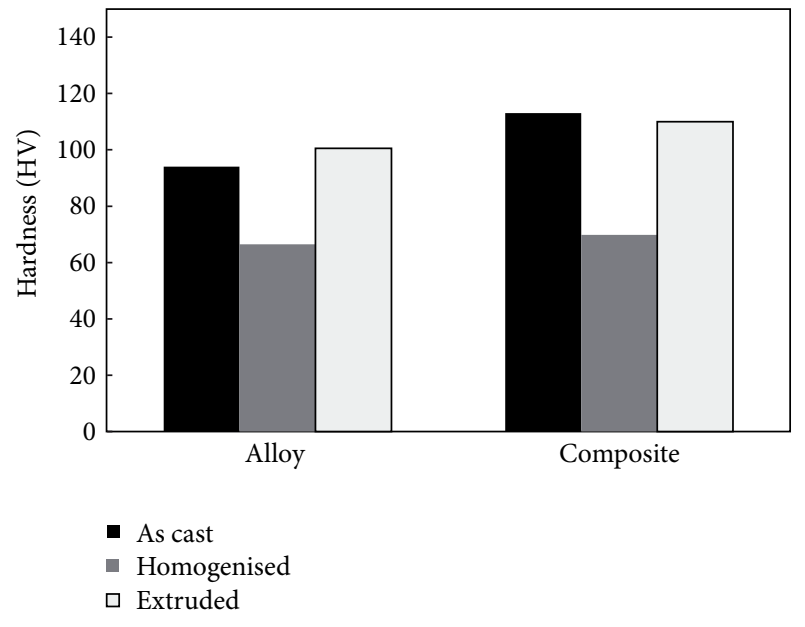

Figure 3: Hardness under different conditions.

sliding wear properties between the extruded alloy and composite. Material properties attained have been correlated to their microstructure and features obtained as observed in SEM of the tested samples.

\section{Materials and Methods}

2.1. Synthesis of Composites. Aluminium based alloy conforming to 2014 system consisting of $\mathrm{Al}-4.4 \% \mathrm{Cu}-0.5 \% \mathrm{Mg}$ $0.8 \% \mathrm{Si}-0.8 \% \mathrm{Mn}$ was chosen for the present study. The alloys were cast into cylindrical billets of $75 \mathrm{~mm}$ diameter using the liquid metallurgy route. For preparing the composites, the alloy was remelted and 10 volume $\% \mathrm{SiC}$ of size range 20-50 $\mu \mathrm{m}$ which was preheated was poured into the melt after passing through a sieve. During insertion of the dispersoid, the melt was stirred constantly by means of a stirrer placed in the melt operated by a motor. After complete insertion of the dispersoids in the molten alloy, the alloy was simultaneously stirred and heated for some time for uniform mixing and temperature. The melt with the dispersoids were then poured into preheated permanent moulds to cast the composites into cylinders of $\sim 75 \mathrm{~mm}$ diameter.

2.2. Extrusion of Composites. A hydraulic press with a capacity of 400 tonne fitted with an extrusion setup was used for the hot extrusion of cylindrical rod by the forward bar extrusion process under optimized extrusion conditions that is, pressing speed of $0.36 \mathrm{~mm} / \mathrm{sec}$ and billet soaking temperature of $350^{\circ} \mathrm{C}$ for 2 hours [23]. Specimens of the alloys 


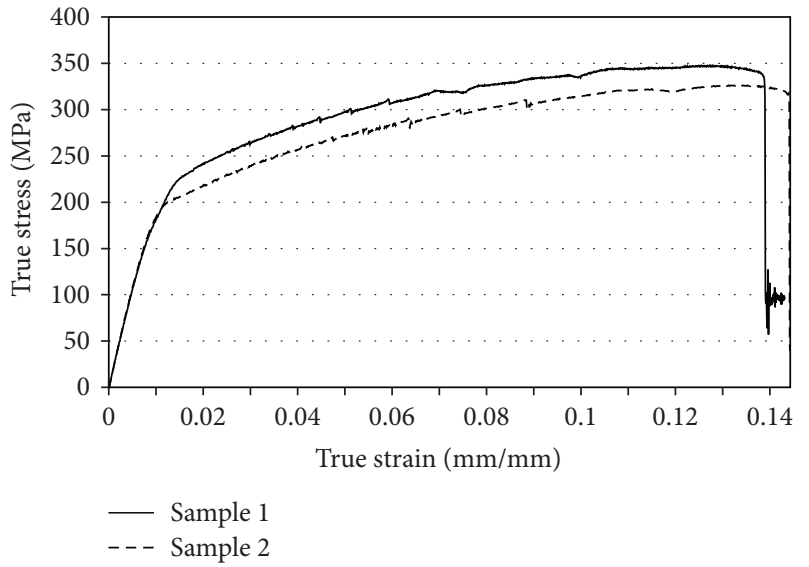

(a)

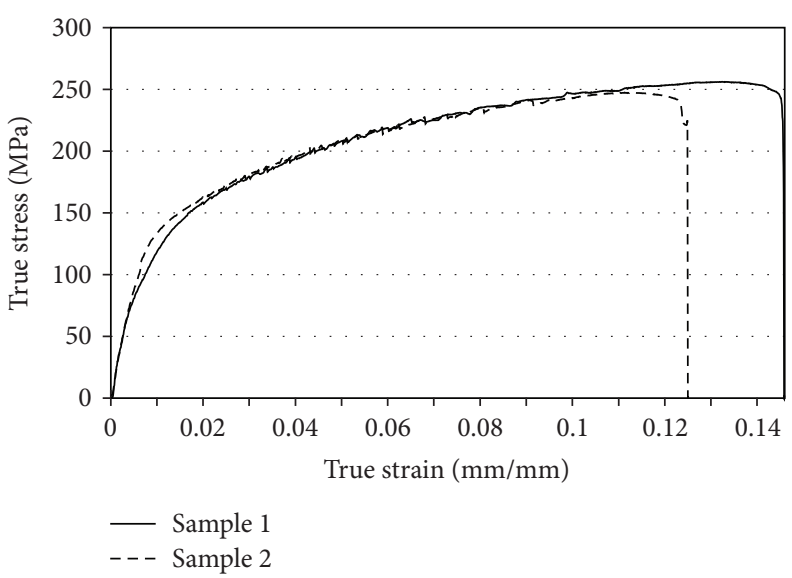

(b)

FIGURE 4: Stress-strain curves for extruded (a) alloy and (b) composites.

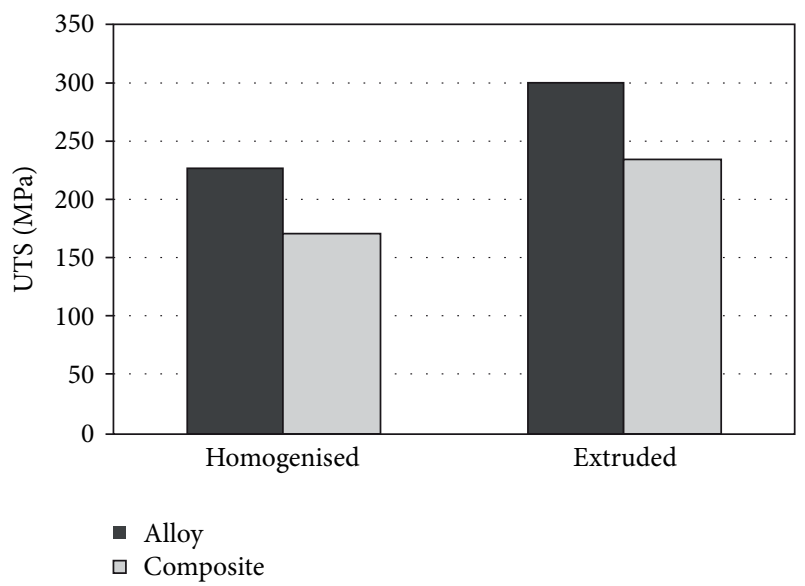

FIGURE 5: UTS for alloy and composite under different conditions.

and composites homogenized at $480^{\circ} \mathrm{C}$ for the period of 12 hours prior to the extrusion were used for the extrusion. The cast billets prior to homogenisation were machined to $50 \mathrm{~mm}$ diameter and $\sim 60 \mathrm{~mm}$ height and extruded using a flat die to cylindrical rods of $15 \mathrm{~mm}$ diameter maintaining an extrusion ration of $10: 1$ in all the cases.

Samples around $20 \mathrm{~mm}$ diameter cut from the cast and extruded specimens were metallographically polished and etched in Kellar's reagent for metallographic studies. The microstructures were observed in the optical microscope and/or JEOL scanning electron microscope operating at $20 \mathrm{KV}$ in the secondary mode of electron emission.

Hardness of the samples was measured on the polished surface using a Vickers's Hardness Tester from K.B. Pruiftechnik, Model No. KB250BVRZ applying a load of $5 \mathrm{Kg}$. An average of at least seven readings was taken at different portions of the sample for comparison between cast and extruded specimens.

The mechanical properties, namely, Yield stress, UTS, and \% elongation in the cast and extruded from both alloy and composite were determined using a Universal Testing Machine, of INSTRON make, Model No. 8801.

Dry sliding wear tests were carried out on samples in the form of pins of $10 \mathrm{~mm}$ diameter and $25 \mathrm{~mm}$ length with a small hole at its end to place the thermocouple, from extruded rods of the alloy and composite. The tests were carried out on a Magnum make wear testing machine as per ASTM G99-05, in which the pin was placed vertically. The pin was made to slide against a rotating stainless steel disc at predetermined speeds of rotation. Using a cantilever, the loads were adjusted. Wear takes place due to the sliding action in the absence of any lubricant. The polished sample was initially used which was slid against the disc before starting the test to make its surface matching with the disc as the running in period. The friction force generated and temperature rise were continuously noted. The weight of the specimen was measured after a fixed interval of time to measure the weight loss which was then converted to volume loss for comparison. The volume loss was plotted against the sliding distance (measured in meters) travelled, calculated as $2 \Pi r t s$, where $r$ is the radial distance on the disc where the pin is placed, $t$ is the time in minutes, and $s$ is the speed of rotation of the disc measured in rpm. Tests were carried out at loads of 1,3 , and $4 \mathrm{Kg}$ and sliding speeds of 400, 700, and $1000 \mathrm{rpm}$ upto sliding distance of $\sim 30,000 \mathrm{~m}$.

The fractured and worn surfaces were observed in an FESEM (FEI make model No. Nova Nano SEM 430) to understand the nature of failure and mechanism of wear removal, respectively.

All the above properties were compared between the extruded alloy and composite to understand improvement on extrusion between alloy and composite.

\section{Results and Discussion}

3.1. Metallographic Studies. The microstructure of the alloy and composites prior to and after extrusion is shown in Figures 1 and 2, respectively. The cast structure (Figures 1(a) and $2(\mathrm{a}))$ is characterized by rounded grains in which the $\mathrm{SiC}$ 


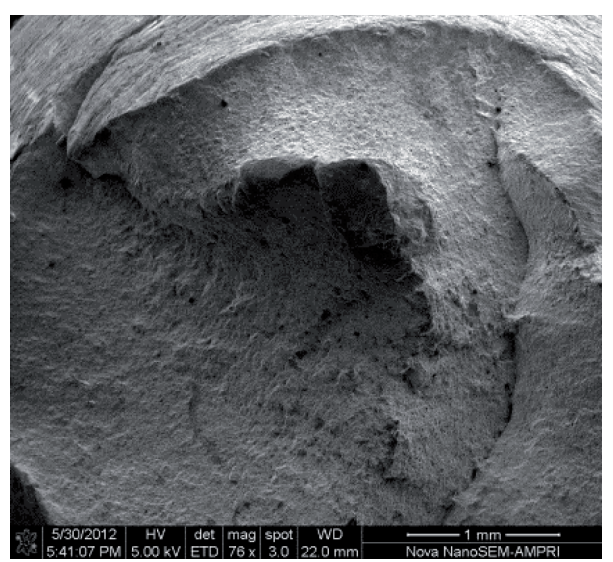

(a)

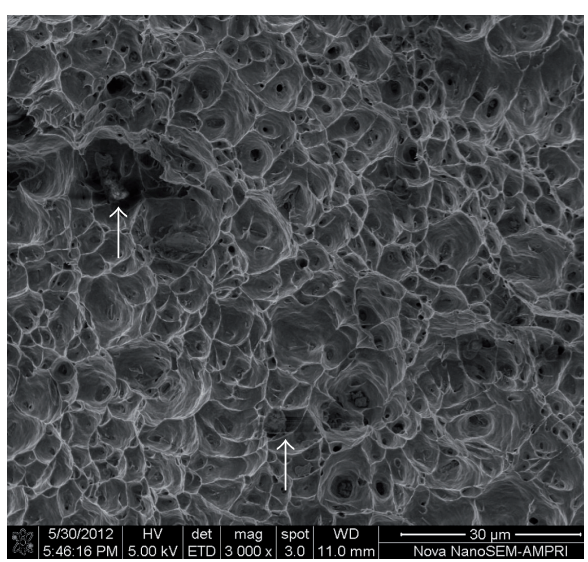

(b)

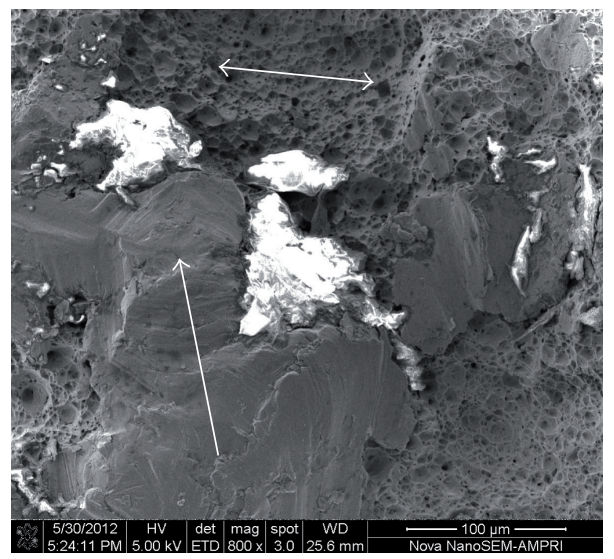

(c)

FIGURE 6: Fractographic representation of composite specimens.

TABLE 1: Tensile properties of extruded specimens.

\begin{tabular}{lcccc}
\hline Sample & UTS, MPa & YS, MPa & Young's Modulus, GPa & Elongation at UTS, \% \\
\hline Extruded alloy & 300.1 & 130 & 35.4 & 14.9 \\
Extruded composite & 233.8 & 100 & 31.7 & 10.3 \\
\hline
\end{tabular}

distribution can be uniformly seen. In the extruded sample (Figures 1(b) and 2(b)), the features are not well resolved; however a directionality can be seen and there is a general breakdown of the cast structure. Presence of the $\mathrm{SiC}$ can be observed but they do not seem to have been broken down in size; this is due to their already small size.

3.2. Hardness. The average hardness of the specimens is shown in Figure 3. It is observed that making composites improves hardness significantly. However as expected, homogenisation softens the matrix and a decrease in hardness is observed both for composite and alloy. Again extrusion improves the hardness in the case of both alloy and composite cast composite even over the cast condition.
Interestingly, it may be noted that the difference between the alloy and composite is maintained even after extrusion.

3.3. Tensile Properties. The stress-strain graph for the extruded alloy and composite is shown in Figure 4 and the average of at least two samples is tabulated in Table 1.

In general, it is found that making composites decreases the strength properties over the base alloy (Figure 5). This is due to the presence of the dispersoids which serve as nucleation sites for fracture. On extrusion, however, strength is improved both for the alloy and composite (Figure 5).

The fractured surface of the composite is shown in Figure 6. At a lower magnification (Figure 6(a)), it is seen that shearing of the material takes place indicative of its ductile nature. The same can be seen at higher magnification (Figure 


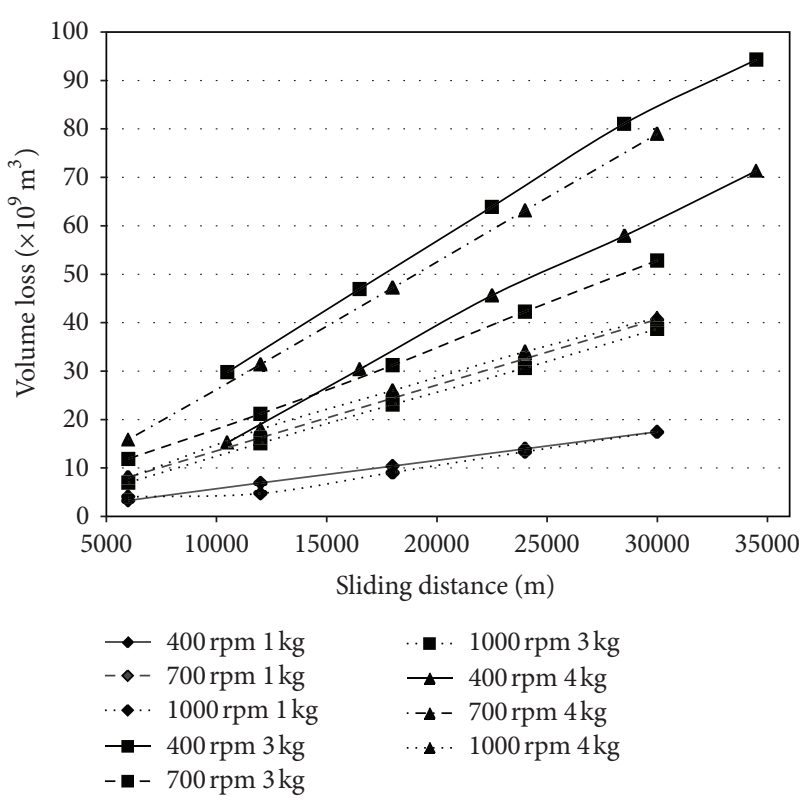

FIGURE 7: Variation of volume loss with sliding distance under different experimental conditions for extruded composite.

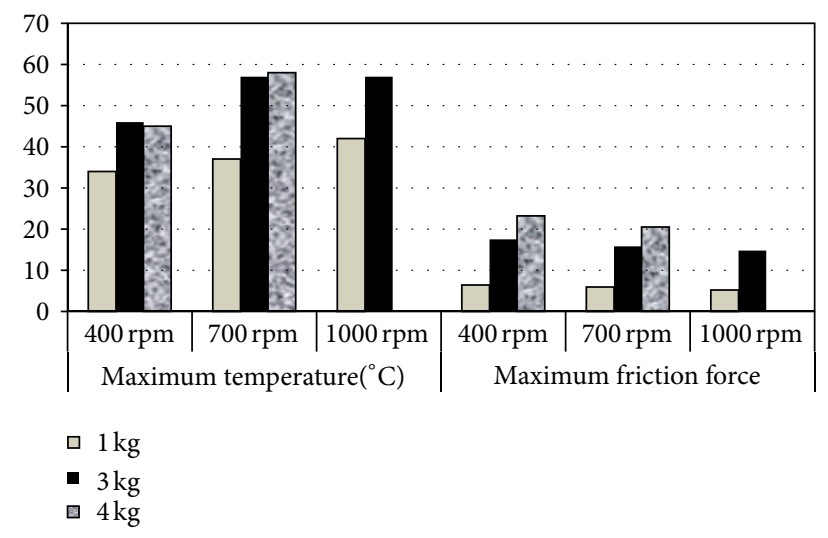

FIGURE 8: Variation of maximum temperature and friction force for composites under different experimental conditions.

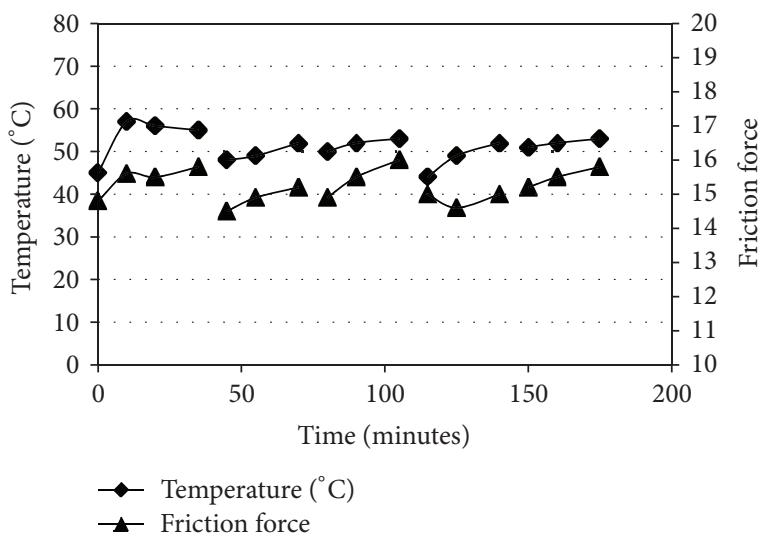

FIGURE 9: Variation of temperature and friction force with time at sliding speed of $700 \mathrm{rpm}$ and $3 \mathrm{Kg}$ load.

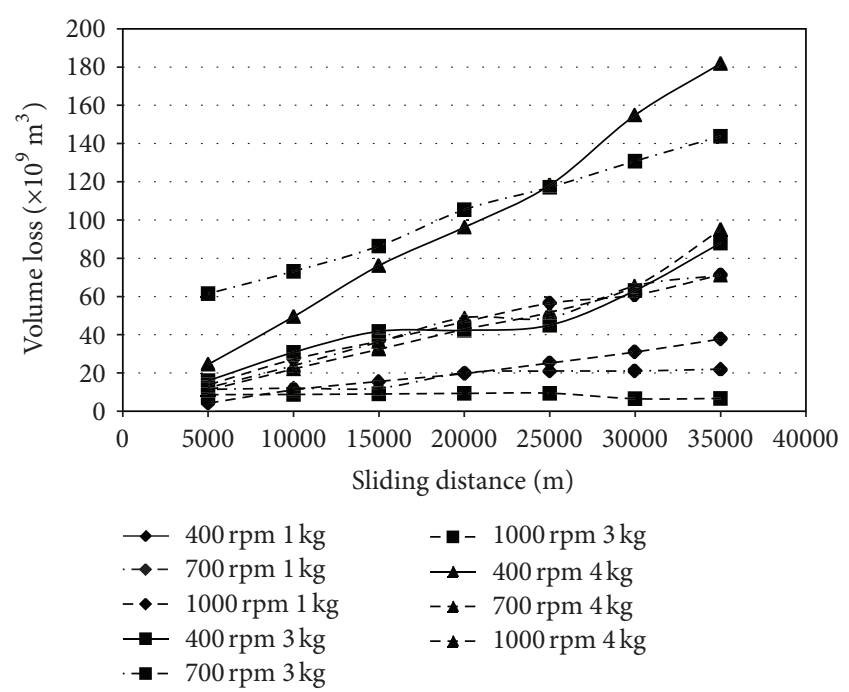

Figure 10: Variation of volume loss with sliding distance for extruded alloy under different experimental conditions.

6(b)) from the cup and cone arrangement of the fractured surface. At some positions, $\mathrm{SiC}$ can be seen encapsulated in the cup (Figure 6(b), marked by arrow) or even in the portions from where the sample has not broken (Figure 6(c)); these dispersoids have been removed too; however, the latter confirms that the dispersed particles do not serve as nuclei for fracture. This could be due to the very small size of the dispersoids in this case. However, in portions the shearing and initiation of breaking takes place close by (Figure 6(c), marked by arrow and double arrow resp.); which is due to the presence of dispersoids and this probably has led to the comparatively lower tensile properties in composites as compared to their base alloy in the extruded condition.

3.4. Sliding Wear Behaviour. The variation of volume loss as a function of different experimental factors for extruded composite is plotted in Figure 7. It is seen that there is a mixed effect of the experimental factors on the volume loss. Maximum volume loss throughout the duration of the test is observed at $400 \mathrm{rpm}$ and $3 \mathrm{Kg}$ load and the minimum at $1000 \mathrm{rpm}$ at $1 \mathrm{Kg}$ load. Increasing only the load and keeping the speed of rotation constant results in higher volume loss; however, increasing speed at a constant load has the reverse effect. It is felt that when the load is increased due to pressure more material is lost but when the speed is increased since the specimen gets less time for contact the material loss is less. Likewise, varying either speed or load can result in improved wear properties (inverse of volume loss) over other experimental conditions.

The maximum temperature rise and friction force during the duration of the test under different experimental conditions plotted in Figure 8 shows a clear increase in the maximum temperature reached with load under all speeds of rotation, but there is a decrease in the frictional force with increased speed of rotation. The lower friction force could be the cause of comparatively material loss under these 


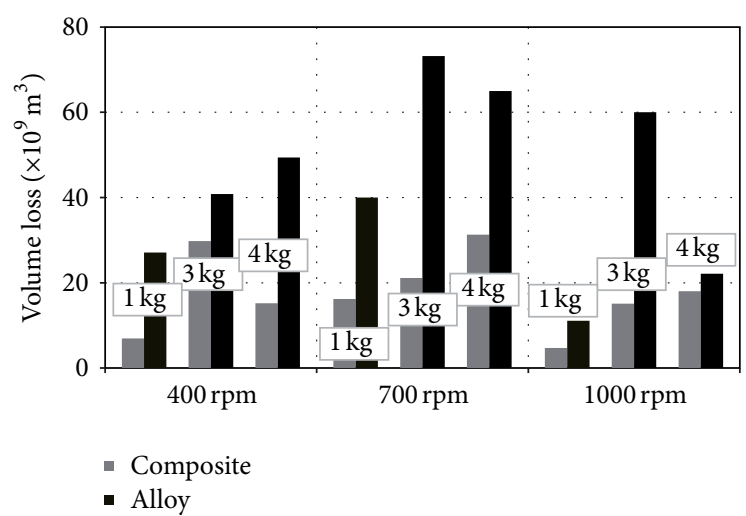

(a) $10,000 \mathrm{~km}$ sliding distance

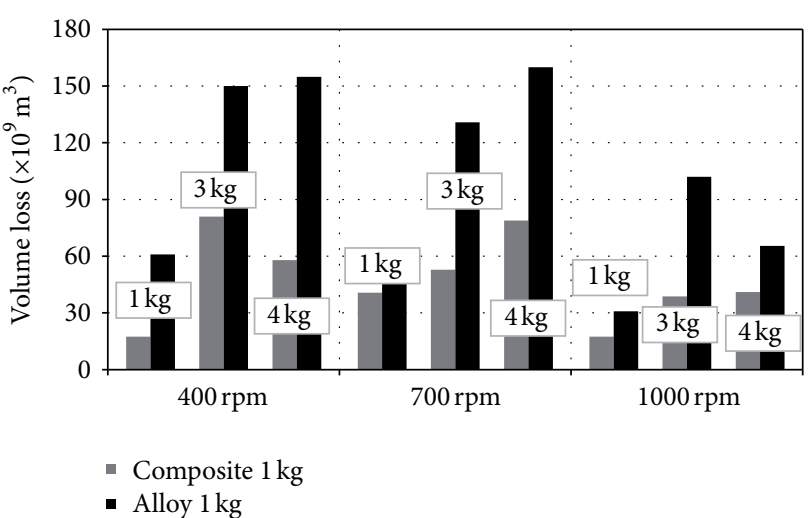

(b) 30,000 Km sliding distance

FIGURE 11: Comparative volume loss of composite and alloy at different experimental conditions.

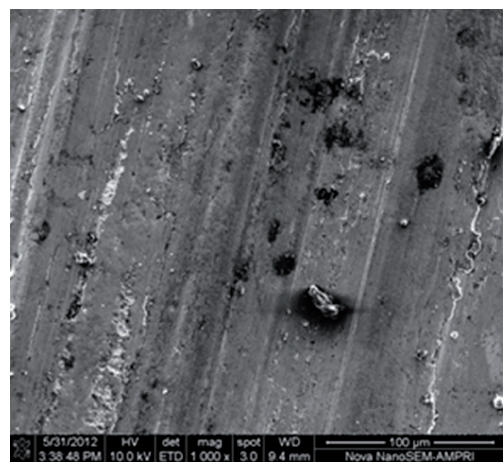

(a)

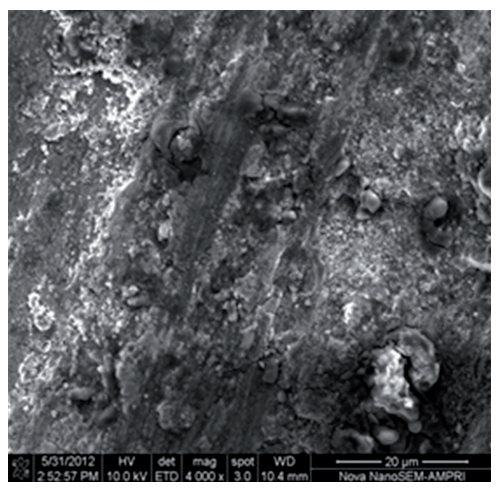

(d)

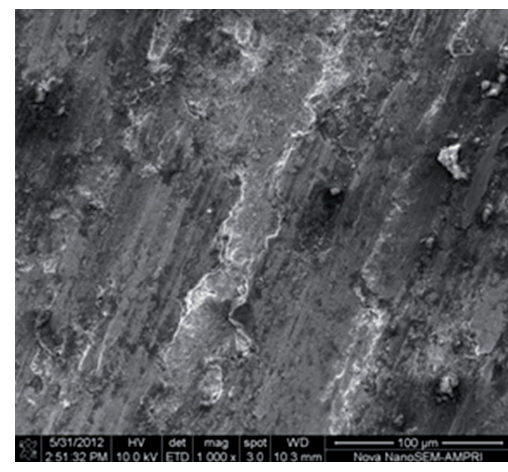

(b)

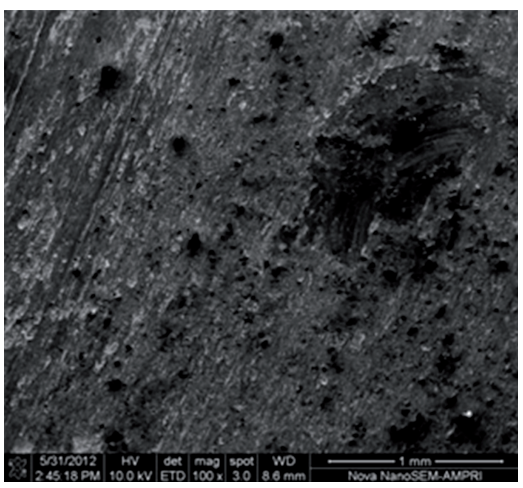

(e)

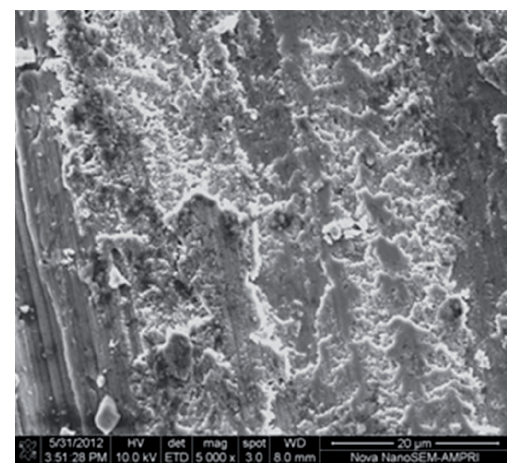

(c)

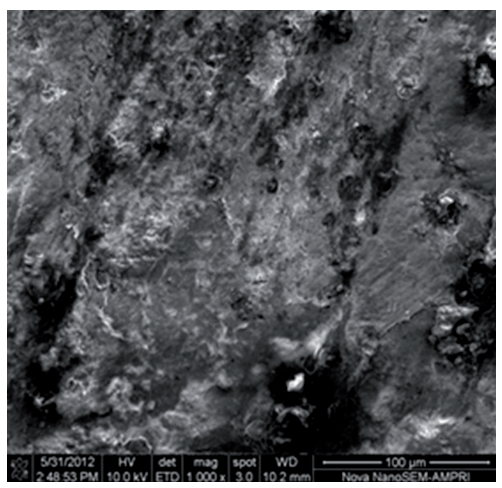

(f)

FIGURE 12: Worn surface of composites under different experimental conditions.

conditions. However, the maximum temperature reached in well below $100^{\circ} \mathrm{C}$ and no signs of seizure have been observed during the tests.

It may also be mentioned that the maximum friction force and maximum temperature are reached quite early during the test and remains around the same value for most part of the duration of the test, exhibiting decrease at intervals when the specimen is unmounted for weight measurements (depicted as gaps in the plot). As an example, a typical plot of the variation of the temperature and friction force with time during a particular experimental set of conditions that at $700 \mathrm{rpm}$ and $3 \mathrm{Kg}$ load is plotted in Figure 9.

As in the case of composite, the extruded alloys too exhibit a mixed response in the behaviour of volume loss with sliding distance with varying experimental conditions of speed and load (Figure 10). In general, highest speed of rotation tested that is, $1000 \mathrm{rpm}$ results in lower volume loss as compared to the lower speeds of 400 and $700 \mathrm{rpm}$. This is due to the less time of contact with high speeds of $1000 \mathrm{rpm}$. This observation is corroborated by the less surface damage 


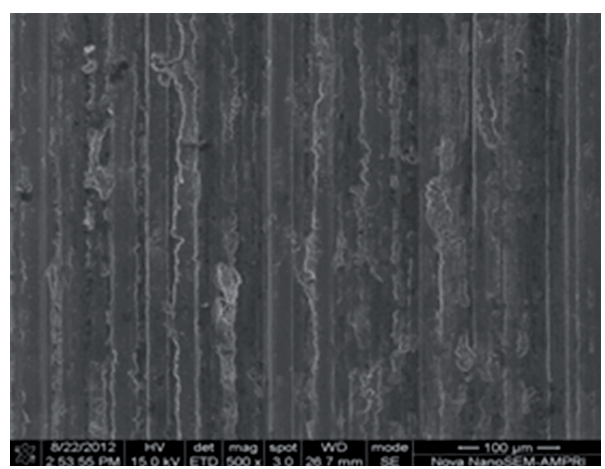

(a)

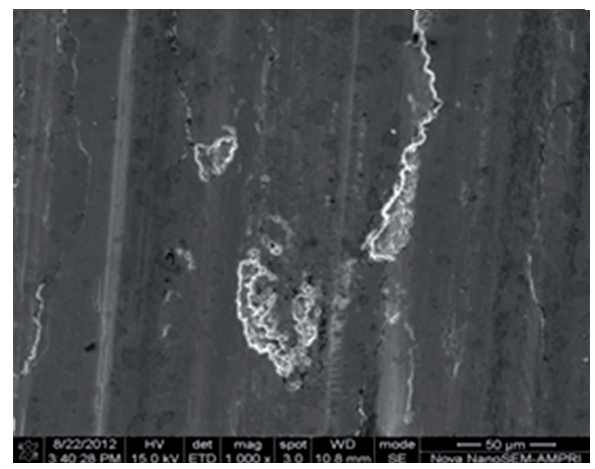

(c)

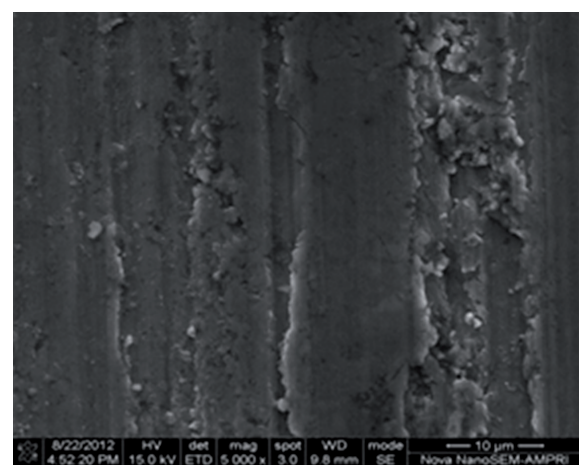

(b)

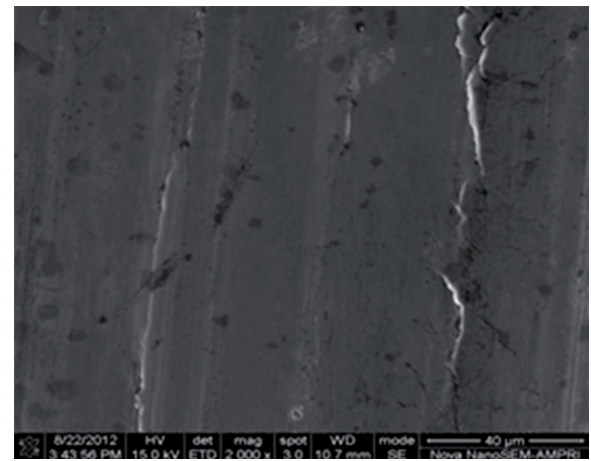

(d)

FIGURE 13: Worn surface depicting features commensurate with observed wear loss.

of the worn surface under high speeds. It is interesting to note that increasing load does not necessarily increase the volume loss at a particular sliding speed in the case of alloy. No seizure has been observed in this case unlike in the case of composites.

A glance comparison of just the $y$-axis scales between Figures 7 and 10 indicates the marked degree of improvement in the wear resistance on making composites. However, for comparison, the volume loss at two sliding distances 10000 and $30000 \mathrm{~m}$ has been compared for the alloy and composite under the different experimental conditions in Figures 11(a) and $11(\mathrm{~b})$, respectively.

Improvement in the wear performance (inverse of volume loss) in composites over the base alloy is attributed to the resistance offered by the $\mathrm{SiC}$ dispersoids in the matrix. The load during wear is taken up by the hard SiC dispersoids saving the matrix from the exposure. This is in accordance with the often quoted improved performance of wear resistance of composites over its matrix alloy. However, in this case due to extrusion, the material has been further strengthened due to consolidation resulting in still better resistance to wear. Thus the improvement in wear performance in the extruded case is expected to be better than the cast conditions; this point however cannot be ascertained as it is not possible to compare the wear behaviour which is a relative phenomenon with past findings. The size of the $\mathrm{SiC}$ dispersoids in this case being very fine would further inhibit wear during sliding as larger particles have the tendency of breaking and falling off thus increases sudden and unpredicted wear/material losses. In this case, however, no breaking of dispersoids has been seen (Figure 12) ruling out material loss from dissociation of particles from dispersoids often seen in composites made from larger $\mathrm{SiC}$ dispersoids [24-27].

3.4.1. Wear Mechanism: Worn Surface. The worn surface of the composites is characterized by wear marks throughout the tested region and it is scattered or continuous depending on the severity of wear; conditions which have exhibited high wear loss have deeper groves. All the above features can be seen on the worn surface (Figure 12) and the surface damage is commensurate with the harshness of the experimental conditions. Under mild conditions of wear like under high speeds of rotation, the material does not come in contact continuously with the rotating disc and hence the wear tracks are not continuous and very shallow (Figures 12(a) and 12(b)). In between the grooves, wear debris can be seen trapped which in all probability these are $\mathrm{SiC}$ dispersoids that have been removed during the process of wear (Figure 12(b) marked by arrow). Due to the sliding action of the specimen surface and rotating wheel, the surface layer of the specimen is affected through the formation of wear tracks. Wear tracks show that the material from in between the tracks loosened up which on further exposure (continuous) to the wear conditions finally gets delaminated and chipped off (Figure 12(c)). The mechanism of wear (material) removal is through delamination of layers (surface) progressively as can be seen in the figure. In cases where severe material loss is recorded, it is possible that the material has completely fallen off (Figures 12(d) and 12(e)). Again, seizure of the 
test specimen is characterized by material flow and sudden change in wear track (Figure 12(f) marked by double arrow). The effect of material damage can be seen in the subsurface region.

The worn surface in the case of alloys observed after completion of the tests is characterised by grooves and material removal between grooves; material overlapping is also observed in case of severe material damage (Figure 13) and in some cases cracking of the surface is also observed. All these features are commensurate with the wear loss; under conditions where less or least wear has been observed shallow grooves are observed (Figure 13(a)); as the conditions get harsher the grooves become deeper and broader and material removal takes place from between the grooves (Figure 13(b)). Material overlap precedes seizure and this relates to severely worn conditions (Figure 13(c)); material cracking has been observed to accompany high damage conditions (Figure 13(d)).

\section{Concluding Remarks}

Al-based 2014 alloy with fine SiC dispersoids (size 20-50 $\mu \mathrm{m}$ ) has been successfully extruded to cylindrical rods along with alloys of the base matrix under identical experimental conditions. Forming composites in general increases the hardness and extrusion further increases it. However, the tensile properties record a decrease in making composites as compared to the alloy.

Dry sliding wear of extruded composites shows a marked improvement over extruded alloys under all conditions of load and speed tested over the entire sliding distance tested. The material removal method in the case of alloys consists of first making groove marks on the surface, then as the conditions continue the grooves get deeper and the material forming a layer on the surface being worn, then this surface could form a layer somewhat elevated from the specimen and then gradually peels off. In the case of composites also material removal is through progressive delamination of worn surface layers. However, the difference in material removal mechanism between the alloy and composite is that in the former under severe conditions of material loss, material is scooped out from the grooves but in the case of composites, the complete layer peels off. This is probably due to the presence of the dispersoids that assist in delamination of the worn layer. Again inspite of the alloy recording much higher wear loss as compared to the composite, seizure is not observed in the former whereas composites tend to seize at even lower material loss if conditions are harsh. Seizure of the test specimen is characterized by machine stopping abruptly and depicted as material flow over layers and change in wear track as seen in the worn surface studies.

\section{References}

[1] S. J. Harris, "Cast metal matrix composites," Materials Science and Technology, vol. 4, no. 3, pp. 231-238, 1988.

[2] I. A. Ibrahim, F. A. Mohamed, and E. J. Lavernia, "Particulate reinforced metal matrix composites-a review," Journal of Materials Science, vol. 26, no. 5, pp. 1137-1156, 1991.
[3] K. Shin, D. Chung, and L. Sunghak, "The effect of consolidation temperature on microstructure and mechanical properties in powder metallurgy-processed 2XXX aluminum alloy composites reinforced with sic particulates," Metallurgical and Materials Transactions A, vol. 28, no. 12, pp. 2625-2636, 1997.

[4] C. S. Rao and G. S. Upadhyaya, "2014 and 6061 aluminium alloy-based powder metallurgy composites containing silicon carbide particles/fibres," Materials and Design, vol. 16, no. 6, pp. 359-366, 1995.

[5] O. P. Modi, A. H. Yegneswaran, R. Asthana, and P. K. Rohatgi, "Thermomechanical processing of aluminium-based particulate composites," Journal of Materials Science, vol. 23, no. 1, pp. 83-92, 1988.

[6] P. K. Rohatgi, S. Das, and R. Asthana, "Science, technology and industrial potential of cast metal ceramic particle composites," in Materials Science and Technology in the Future, pp. 123-184, CSIR, Bhopal, India, 1985.

[7] M. Rosso, "Ceramic and metal matrix composites: routes and properties," Journal of Materials Processing Technology, vol. 175, no. 1-3, pp. 364-375, 2006.

[8] D. B. Miracle, "Metal matrix composites-From science to technological significance," Composites Science and Technology, vol. 65, no. 15-16, pp. 2526-2540, 2005.

[9] L. M. Tham, M. Gupta, and L. Cheng, "Effect of limited matrixreinforcement interfacial reaction on enhancing the mechanical properties of aluminium-silicon carbide composites," Acta Materialia, vol. 49, no. 16, pp. 3243-3253, 2001.

[10] A. J. Shakesheff and G. Purdue, "Designing metal matrix composites to meet their target: particulate reinforced aluminium alloys for missile applications," Materials Science and Technology, vol. 14, no. 9-10, pp. 851-856, 1998.

[11] E. M. Ruiz-Navas, M. L. Delgado, and J. M. Torralba, "Development of aluminium alloys and metal matrix composites by powder metallurgy," in 4th International Conference on Materials and Manufacturing Technologies, MATEHN'06, pp. 51-58, rou, September 2006.

[12] M. Asif, K. Chandra, and P. S. Misra, "Development of aluminium based hybrid metal matrix composites for heavy duty applications," Journal of Minerals and Materials Characterization and Engineering, vol. 10, no. 14, pp. 1337-1344, 2011.

[13] J. Jiang, C. Collado, D. Keeley, and B. Dodd, "Room temperature formability of particle-reinforced metal matrix composites: forging, extrusion and deep drawing," Composites, vol. 26, no. 11, pp. 785-789, 1995.

[14] S. Rawal, "Metal-matrix composites for space applications," Journal of Management, vol. 53, no. 4, pp. 14-17, 2001.

[15] B. Dutta, I. Samajdar, and M. K. Surappa, "Particle redistribution and matrix microstructure evolution during hot extrusion of cast SiCp reinforced aluminium alloy matrix composites," Materials Science and Technology, vol. 14, no. 1, pp. 36-46, 1998.

[16] Y. H. Seo and C. G. Kang, "Effects of hot extrusion through a curved die on the mechanical properties of $\mathrm{SiCp} / \mathrm{Al}$ composites fabricated by melt-stirring," Composites Science and Technology, vol. 59, no. 5, pp. 643-654, 1999.

[17] K. Hanada, Y. Murakoshi, H. Negishi, and T. Sano, "Microstructures and mechanical properties of $\mathrm{Al}-\mathrm{Li} / \mathrm{SiCp}$ composite produced by extrusion processing," Journal of Materials Processing Technology, vol. 63, no. 1-3, pp. 405-410, 1997.

[18] R. K. Goswami, R. Sikand, A. Dhar, O. P. Grover, U. C. Jindal, and A. K. Gupta, "Extrusion characteristics of aluminium 
alloy/SiCp metal matrix composites," Materials Science and Technology, vol. 15, no. 4, pp. 443-449, 1999.

[19] L. M. Tham, M. Gupta, and L. Cheng, "Effect of reinforcement volume fraction on the evolution of reinforcement size during the extrusion of Al-SiC composites," Materials Science and Engineering A, vol. 326, no. 2, pp. 355-363, 2002.

[20] I. Flitta and T. Sheppard, "Nature of friction in extrusion process and its effect on material flow," Materials Science and Technology, vol. 19, no. 7, pp. 837-846, 2003.

[21] M. K. Surappa, "On the nature of particle flow during extrusion of cast $6061 \mathrm{Al} / \mathrm{SiCP}$ composites," Journal of Materials Science Letters, vol. 12, no. 16, pp. 1272-1273, 1993.

[22] G. Abouelmagd, "Hot deformation and wear resistance of $\mathrm{P} / \mathrm{M}$ aluminium metal matrix composites," Journal of Materials Processing Technology, vol. 155-156, pp. 1395-1401, 2004.

[23] R. Dasgupta, S. Das, and A. K. Jha, "Sliding wear behaviour of Al-7075 based metal matrix composite: effect of processing parameters," Key Engineering Materials, vol. 504-506, pp. 555-[60, 2012.

[24] B. K. Prasad, K. Venkateswarlu, A. K. Jha et al., "Sliding wear response of an $\mathrm{Al}-\mathrm{Cu}$ alloy: the influence of $\mathrm{SiC}$ particle reinforcement and test parameters," Journal of Materials Science Letters, vol. 17, no. 13, pp. 1121-1123, 1998.

[25] S. Das, D. P. Mondal, O. P. Modi, and R. Dasgupta, "Influence of experimental parameters on the erosive-corrosive wear of AlSiC particle composite," Wear, vol. 231, no. 2, pp. 195-205, 1999.

[26] R. Dasgupta and H. Meenai, "Sliding wear properties of Al$\mathrm{Cu}$ based alloys with $\mathrm{SiC}$ particle reinforced composites under varying experimental conditions," Journal of Materials Science Letters, vol. 22, no. 22, pp. 1573-1576, 2003.

[27] S. Das, D. P. Mondal, R. Dasgupta, and B. K. Prasad, "Mechanisms of material removal during erosion-corrosion of an AlSiC particle composite," Wear, vol. 236, no. 1-2, pp. 295-302, 1999. 

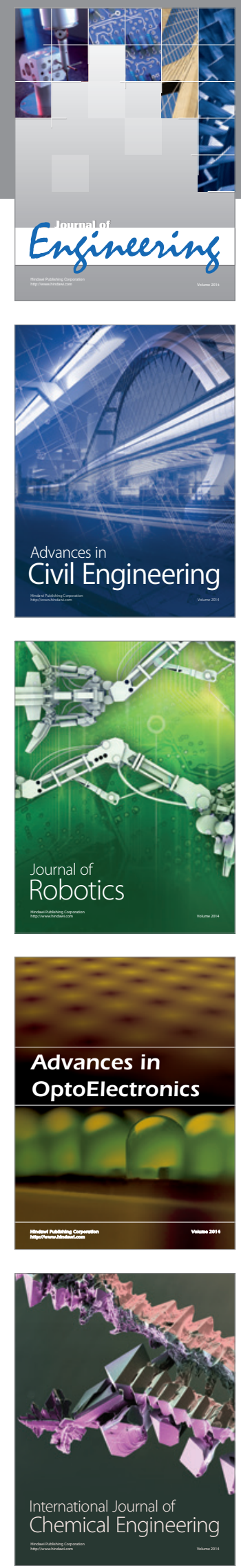

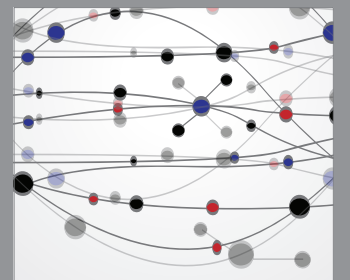

The Scientific World Journal
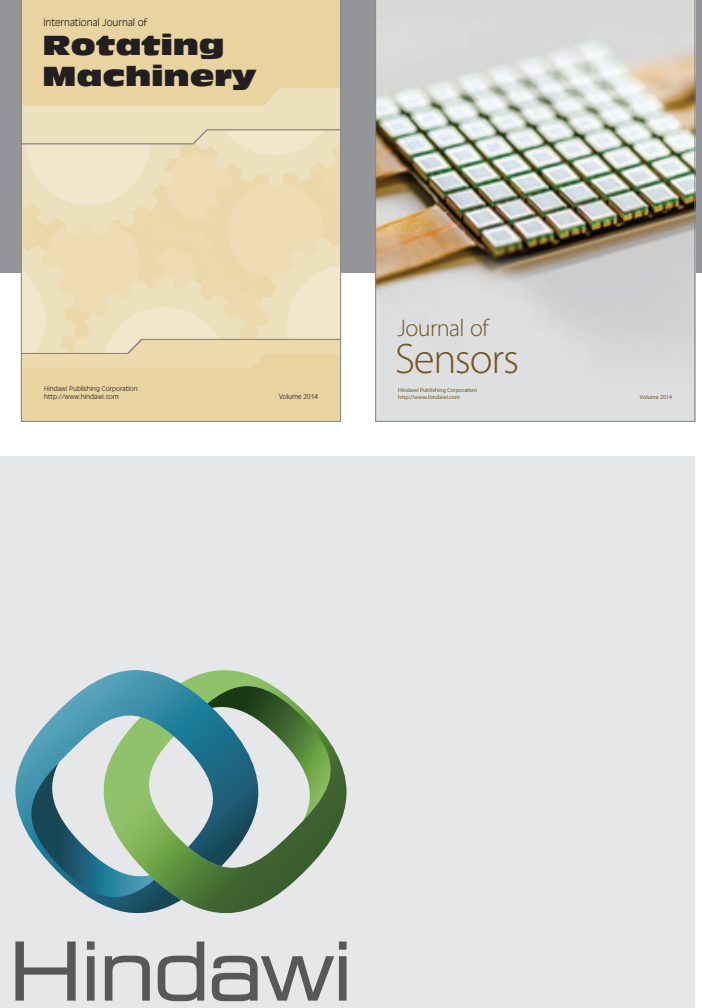

Submit your manuscripts at http://www.hindawi.com
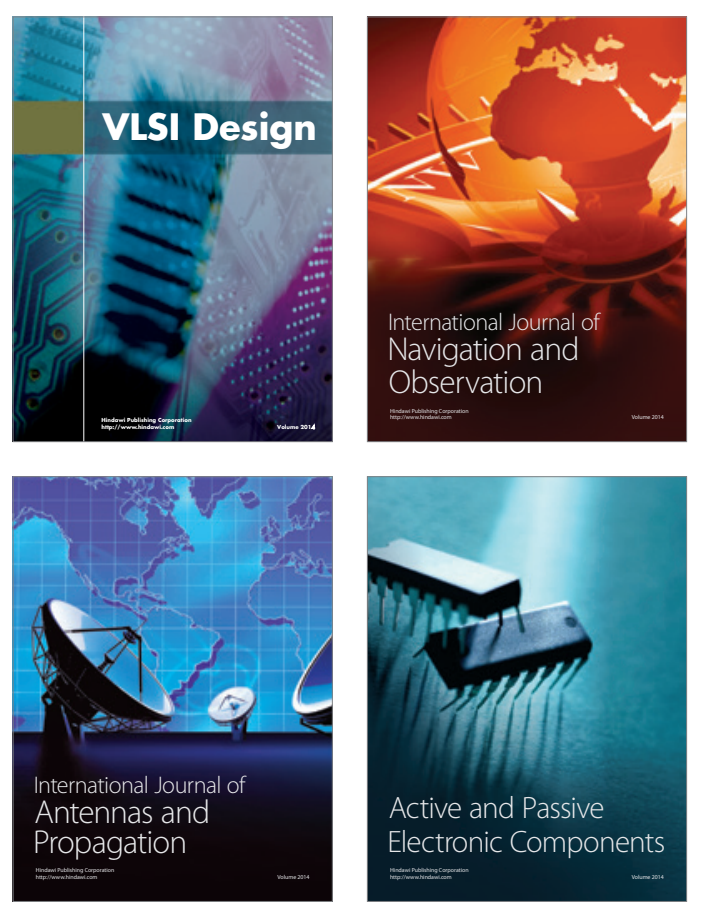
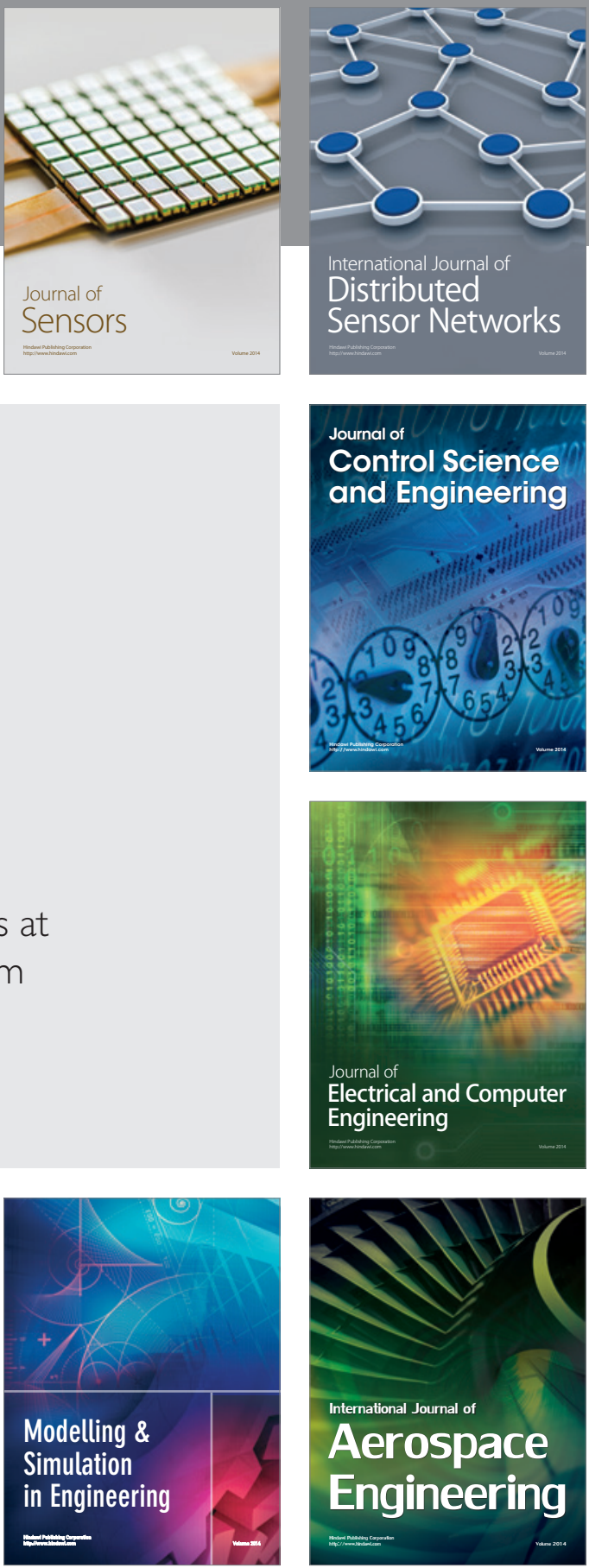

Journal of

Control Science

and Engineering
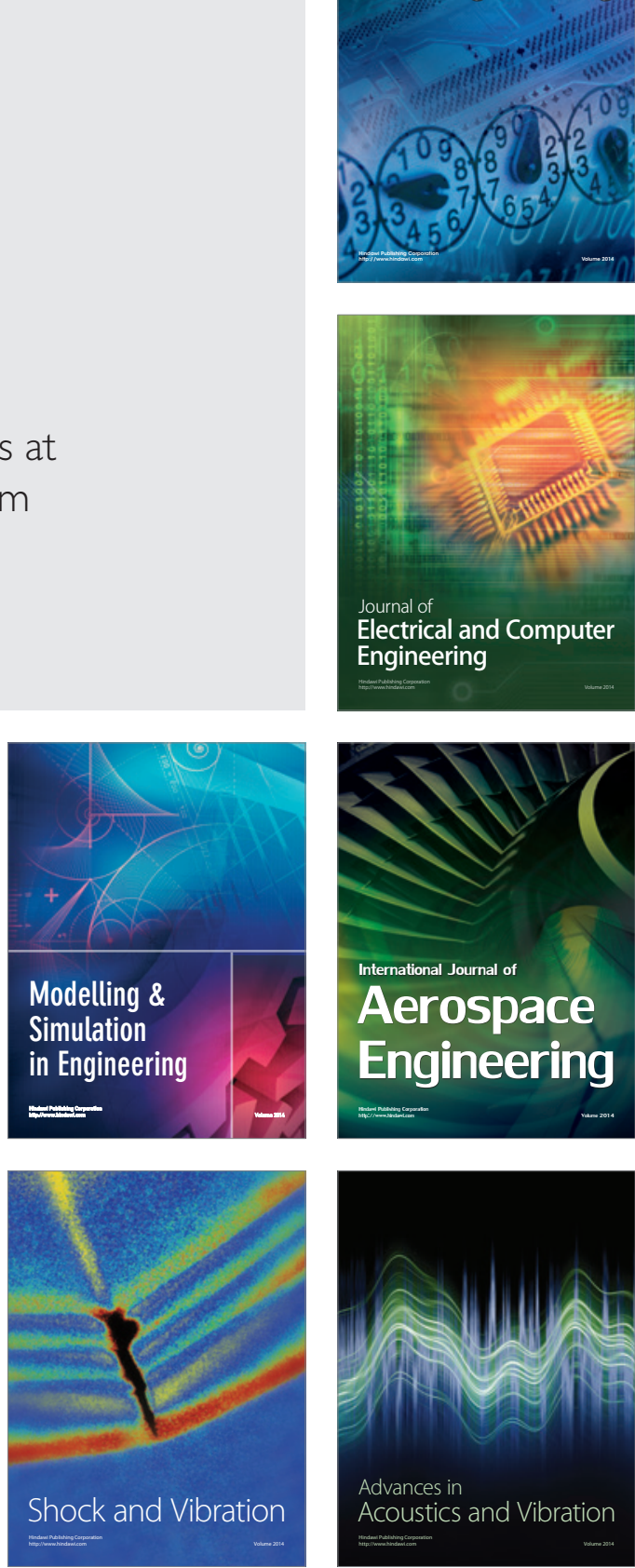